\title{
A retrospective study about the trend analysis of industrial accidents in
}

\section{Pakistan}

\begin{abstract}
:
Background: Occupational accidents in developing countries like Pakistan are obvious due to poor occupational health safety infrastructure. Objective: This retrospective study aimed to analyze the industrial accidents in factories of Pakistan during 1993-2009. Methods: An index value calculation method used to investigate the trends of occupational accidents. Accident rate $\left(10^{3}\right)$, fatal accident rate (105), and non-fatal accident rate (103) were also calculated. Pakistan Statistical Year Books published by Pakistan Bureau of Statistics (PBS) used as data source. Result: Data of total 10330 industrial accidents analyzed and decreasing accident rate found with average 3.1 accident per $10^{3}$ factory workers. Fatal accident increased with an average of 23 fatal accidents per $10^{5}$ factories workers. Regarding the severity of industrial accidents, minor accidents found at $74 \%$ followed by serious (18\%) and fatal accidents (8\%). Decreased trends of index values and accident rates can associate with the increased human development index of Pakistan, but increased fatal accidents in factories and under-reporting are major areas of concern for safety stakeholders. Conclusion: Despite industrial accidents decreased in factories but more in depth studies with more recent data about the root causes of accidents can be useful to draw a true picture of occupational accidents in Pakistan. Improved social security system in Pakistan can be helpful to the exact recording of occupational accidents data.
\end{abstract}

Key Words: Occupational epidemiology; Accident Analysis; Industrial Accidents, Pakistan

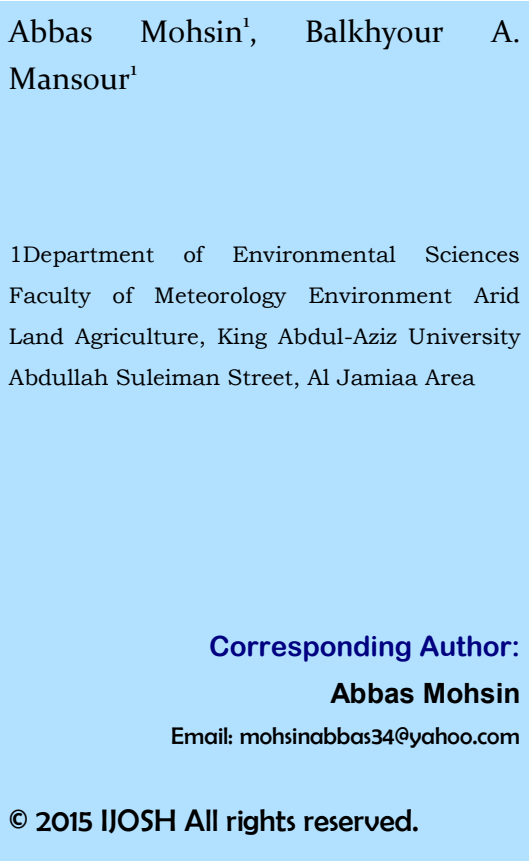

are recording this kind of data. According to ILO, More than half countries lack occupational accidents and disease data. Just a few countries are collecting occupational accidents and illness data gender wise categories. Work-related deaths and injuries are high in developing countries due to involvement by their labor force in hazardous jobs in different sectors such as agriculture, fishing, and mining [1].

Pakistan is a semi-industrialized country ranked World's 10th largest country by its labor force size. Most of the labor force in Pakistan belong to rural areas, and they lack proper medical facilities and compensation for occupational accidents and injuries. Employees social security institutes (ESSI) at the provincial level, providing medical facilities and compensation to the establishments that registered with them. However, still due to lack of proper safety reporting and notifying culture in the country some work related accidents and injuries data lost each year. Factories act-1934 is the main occupational health safety law for worker health safety issues. All factories registered under this law and obligatory for reporting. The direct and indirect cost 
poses by occupational accidents and injuries make a worse situation due they are under-reporting.

A limited number of studies found in the literature regards occupational accidents/injuries in Pakistan. Previously Pasha and Liesivuori (2003) made a comprehensive profile study of occupational health safety in Pakistan [5]; Abbas, (2015) made national level study about the trends of occupational injuries/diseases in Pakistan [6], but not any study found regarding occupational accidents trends investigation, so the aim of this study is to analyze occupational accidents in Pakistan between 1993 and 2009.

\section{Methods}

We used Pakistan Statistical Year Books as data source published by Pakistan Bureau of Statistics (PBS) between 1993 and 2009. Pakistan Bureau of Statistics (PBS) is responsible for keeping up and publish labor force data at governmental level in the country. The last four years data from 2010 to 2013 is not available. Most relevant data of industrial accidents extracted of reporting factories registered under the Factories act-1934. According to this act registered industrial establishments has to report all industrial accidents in corresponding labor and human resources department on specified forms. This Act consolidates and amends the laws on the regulation of labor in factories in Pakistan. This act deals with health and safety of workers, hygiene conditions at the workplaces, factory inspections, and hygienic conditions precaution in case of fire, machine guarding and pressure vessels.

In this study, an index value calculation method used to determine the trends of industrial accidents in the reporting factories in Pakistan between 1993 and 2009. This index value calculation method already used in different studied for trend investigation of occupational injuries/diseases and occupational accidents [6-9]. The index values calculation method used to determine industrial accidents trends based on the starting year (1993) values of industrial accidents in factories and one variable as a reference to a criterion. The index value is the ratio between the numbers of an industrial accident in a year to the reference year (1993) and the ratio between the numbers of industrial accidents to the reference group (minor accidents). It is a useful method to compare trends of industrial accidents both yearly and between the groups. The index values analyzed by calculating the slope value $(S)$ to investigate the downward and upward trends of industrial accidents in reporting factories.

This study defined industrial accident as an unexpected and unplanned occurrence, including acts of non-consensual violence arising out of or in connection with work which results in personal injury, disease or death and fatal occupational injury defined as an occupational injury which leads to death within one year of the day of the occupational accidents causing the injury [10]. Pakistan factory act-1934 defined "factory" means any premises, including the precincts thereof, wherein ten or more workers are working, or were working on any day of the preceding twelve months, and in any part of which a manufacturing process is being carried on or is ordinarily carried on with or without the aid of power, but does not include a mine, subject to the operation of the Mines Act, 1923 [11].

Fatality rate (105) calculated by assuming all reporting factories workers as the denominator in studying years and fatal accidents in the same studied year as nominator. Industrial accidents were categories by PBS as fatal, serious and minor and total of all these accidents termed as total accidents. Nonfatal accidents considered as the total of minor and serious accidents in this study. Nonfatal accident rate (NFAR, 103) calculated by assuming all workers in reporting factories as the denominator in studying years and all non-fatal accidents in the same studied year as nominator.

Total 33297 reporting factories found between 1993 and 2008 in Pakistan and total 2909197 factories workers employed at an annual average of 193946 between 1993 and 2007. The values of 2008 and 2009 and the data of last six years is not available in the Pakistan Statistical Year Books. The trend determination of occupational accidents is useful to establish governmental priorities about the implementation of prevention rules and is crucial in determining indicators of work life $[12,13]$.

\section{Results}

Table 1: The number of factories workers, total industrial accidents, fatal accidents, serious accidents, minor accidents and non-fatal accidents in Pakistan during 1993-2009

\begin{tabular}{|c|c|c|c|c|c|c|}
\hline Year & $\begin{array}{c}\text { Factories } \\
\text { Workers }\end{array}$ & $\begin{array}{c}\text { Total } \\
\text { industrial } \\
\text { accidents }\end{array}$ & $\begin{array}{c}\text { Fatal } \\
\text { acci- } \\
\text { dents }\end{array}$ & $\begin{array}{c}\text { Serious } \\
\text { accidents } \\
(\mathrm{A})\end{array}$ & $\begin{array}{c}\text { Minor } \\
\text { acci- } \\
\text { dents } \\
(\mathrm{B})\end{array}$ & $\begin{array}{c}\text { Non-fatal } \\
\text { accidents } \\
(\mathrm{C}=\mathrm{A}+\mathrm{B})\end{array}$ \\
\hline 1993 & 255943 & 1372 & 87 & 292 & 993 & 1285 \\
\hline 1994 & 256620 & 1137 & 36 & 144 & 957 & 1101 \\
\hline 1995 & 231745 & 1694 & 42 & 123 & 1530 & 1652 \\
\hline 1996 & 188791 & 1216 & 40 & 172 & 1004 & 1176 \\
\hline 1997 & 209925 & 447 & 38 & 55 & 355 & 409 \\
\hline 1998 & 196933 & 453 & 33 & 79 & 341 & 419 \\
\hline 1999 & 169083 & 352 & 20 & 51 & 281 & 331 \\
\hline 2000 & 150255 & 183 & 29 & 122 & 33 & 155 \\
\hline 2001 & 167381 & 377 & 57 & 80 & 239 & 320 \\
\hline 2002 & 156416 & 264 & 46 & 80 & 138 & 218 \\
\hline 2003 & 185188 & 354 & 32 & 103 & 219 & 322 \\
\hline 2004 & 181872 & 404 & 34 & 68 & 302 & 370 \\
\hline 2005 & 183807 & 415 & 38 & 101 & 276 & 377 \\
\hline 2006 & 188183 & 438 & 50 & 106 & 282 & 388 \\
\hline 2007 & 187055 & 460 & 85 & 130 & 245 & 375 \\
\hline 2008 & - & 439 & 108 & 92 & 239 & 331 \\
\hline 2009 & - & 326 & 45 & 62 & 219 & 281 \\
\hline $\begin{array}{l}\text { Aver- } \\
\text { age }\end{array}$ & 193946 & 608 & 48 & 109 & 450 & 559 \\
\hline
\end{tabular}


The number of factories workers, total industrial (factories) accidents, fatal accidents, serious accidents, minor accidents and non-fatal accidents in Pakistan between 1993 and 2009 are shown in Table 1.

Figure 1: Index value trends of factories workers and industrial accidents in the factories of Pakistan during 1993-2009

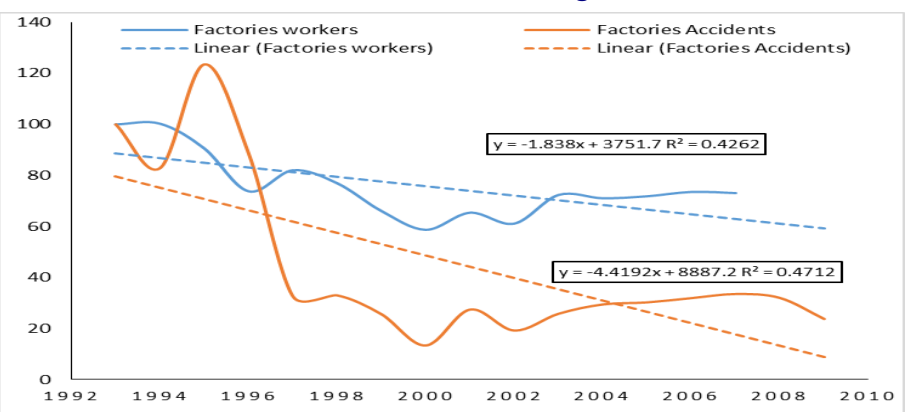

Data of total 10330 factories accidents analyzed, and it was observed that factories accidents decreased after 1996 and oscillated up to 2009 in the country. When we take the year 1993 as a reference, the index values of factories accidents decreased to $23.8 \%$ in the year $2009(S=-4.4)$ largely as compared to the index values of factories workers as figure 1 shows the Index value trends of industrial accidents and factories workers in Pakistan between 1993 and 2009.

Figure 2: Percentage distribution of fatal and non-fatal industrial accidents in the factories of Pakistan during; 1993-2009

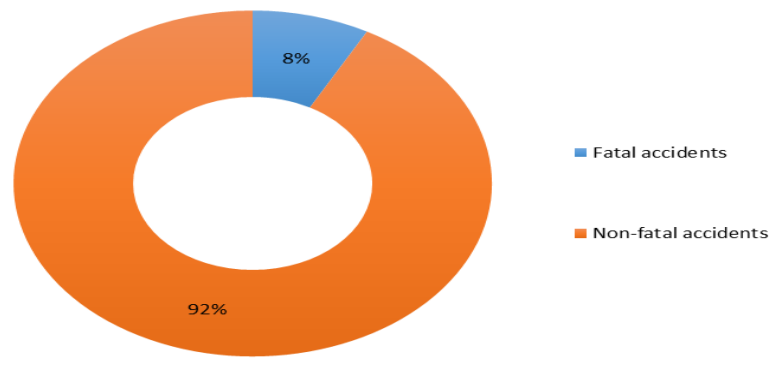

Non-fatal accidents found with an average of 92\% (9511 non-fatal accidents) as figure 2 shows the pie chart of percentage distribution of types of factories accidents in Pakistan between 1993 and 2009 .

Figure 3. Pyramid of severity of industrial accidents in the factories of Pakistan during 1993-2009

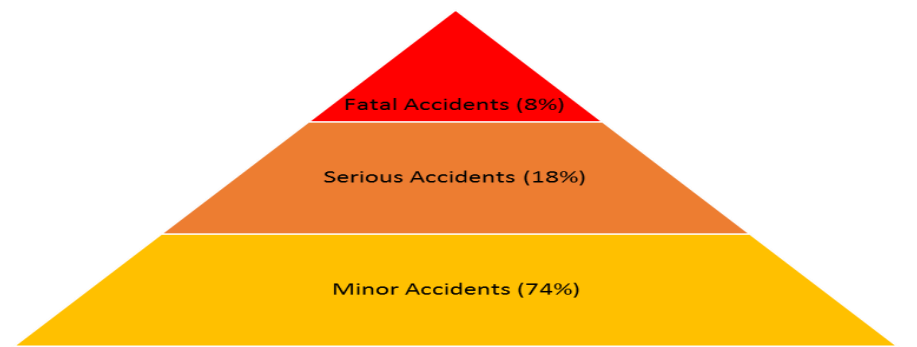

In terms of severity of industrial accidents, minor accidents found with highest percentage $74 \%(n=7653)$, followed by serious accidents $18 \%(n=1858)$ and fatal accidents $8 \%(n=819)$ as figure 3 shows the pyramid of severity of factories accidents distribution in Pakistan between 1993 and 2009.
Table 2: Index values of industrial accidents severity in the factories of Pakistan during 1993-2009

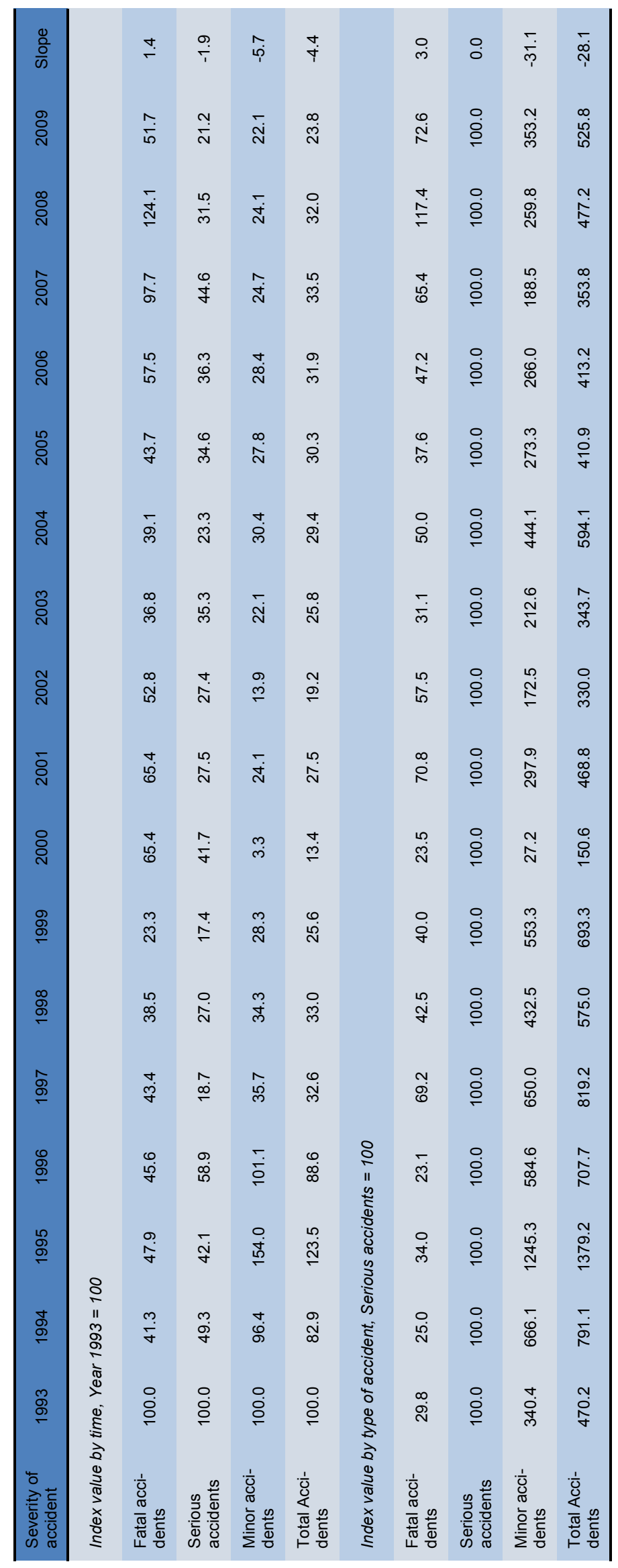


When we take the year 1993 as a reference, the index values of minor accidents, serious accidents, and total accidents decreased, and index values of fatal accidents increased as Table 2 shows the Index values analysis of minor accidents, serious accidents, fatal accidents and total accidents in Pakistan between 1993 and 2009. When we take serious accidents as a reference, the index values of minor accidents and total accidents increased reached to $353.2 \%$ and $525.8 \%$ in 2009 as Table 2 shows Index values of industrial accidents severity in the factories of Pakistan during 1993-2009. In 2008, index values of fatal accidents observed $117.4 \%$ as compared to serious accidents.

Figure 4. Fatal accident rate, non-fatal accident rate and overall accident rate in the factories of Pakistan during; 1993-2007

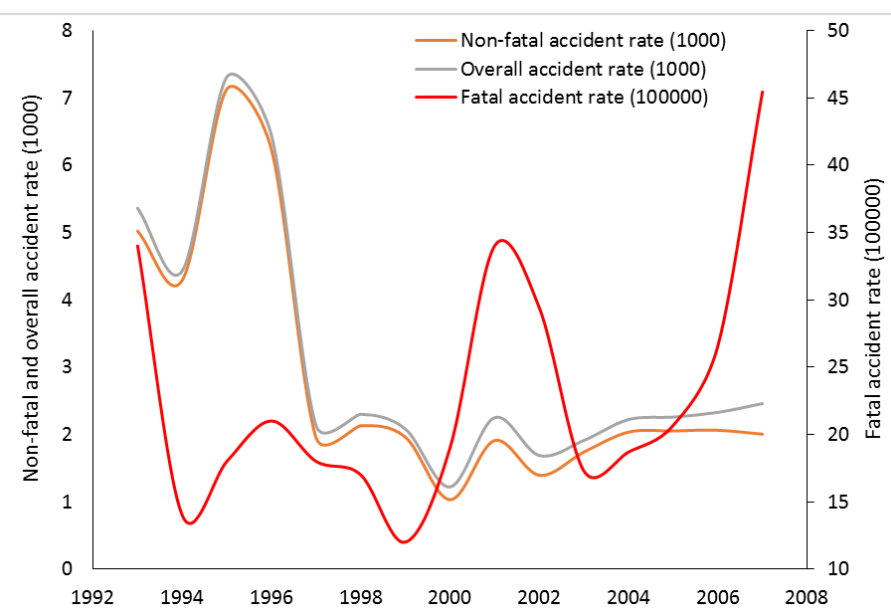

Average fatal accident rate (FAR) found at an average of 23 fatal accidents per 105 factories workers between 1993 and 2007 as figure 4 shows the trends of FAR, NFAR, and overall AR in Pakistan between 1993 and 2007. FAR increased two times after 2003 due to a significant number of fatal accidents in factories. Annual NFAR found at an average of 2.9 non-fatal accident per 103 factories between 1993 and 2007. Higher NFAR observed between 1993 and 1996 and later decreased up to the year 2007. Overall AR found at an average of 3.1 accident per 103 factories workers in the studied years.

\section{Discussion}

Industrial accidents frequently observed in Pakistan, particularly fatal accidents that entail direct and indirect costs. Occupational accidents are the outcomes of poor health safety infrastructure within a country and relative workplace. The poor performance of occupational health and safety influenced by macro factors such as; economic pressure, local regulations organizational structure and financial performance [14]. Worker's health \& safety awareness, perception or occupational risks and their behavior can also be micro factors for the occurrence of occupational accidents [15]. Occupational accidents analysis and injuries are significant to understand their relative risks and development of prevention strategies. The situations in developing countries are graver than developed countries due to lack of safety resources allocation for improving safety status. It is the first study to the trend analysis of industrial accidents in factories during 1993-2009 in Pakistan. We also used Hämäläinen et. al. (2009) study results of the Global trend of occupational accidents at country level to compare our findings to check the trend of occupational accidents in Pakistan [3].

This study found that Overall AR rate decreased after 1996 in Pakistan, which satisfy the finding of [3] in which decreasing accident rate observed between 1998 and 2003. This study found four times decrease in industrial accidents between 1993 and 2009 in Pakistan. The downward trend of AR in Pakistan can also relate to economic development in this span as the value of human development index (HDI) increased during studied years as figure 5 shows the trend of the HDI in Pakistan between 1990 and 2014. The Human Development Index (HDI) is a summary measure of average achievement in the main dimensions of human development: a long and healthy life, being knowledgeable and have a decent standard of living [16].

This study found increased FAR per 105 trends with a discontinuous pattern in Pakistan in studied years which contradict with the findings of [3] in which decreasing fatality rate found in Pakistan between 1998 and 2003. Increased FAR per 105 from 2005 to 2009 can be due to poor safety management in factories. The pattern of NFAR per 103 found similar to overall AR per 103 in factories as $92 \%$ of industrial accidents were non-fatal.

Previously under-reporting of occupational accidents in Pakistan mentioned in a study [5]. The absence of proper social insurance program in Pakistan can be the primary reason for underreporting of industrial accidents data. Due to limitations in available data we are unable to discuss the percentage distribution of hazards by type of industry division but labor force survey (LFS) data about occupational injuries among employed person can be useful to understand it. According to PBS data of LFS from 2001-02 to 2012-13 manufacturing industry division account $14.4 \%$ employed person ten years of age and over suffered occupational injuries/diseases in Pakistan and its index values trend also decreased [6].

It is mentioned in Pakistan Factories Act, 1934 that it is the responsibility of factory manager to report any accident that causes death or injury to the worker's body due to which worker is unable to resume his work in the factory during the 48 hours after the accident occurred to assigned authorities. This act makes assure the reporting of occupational accidents in Pakistan, a factory manager who will not report the accident as happened under $33-\mathrm{N}$ to the assigned authorities will punish with fine may extend to 20,000 Pakistani Rupees equal to 195.37 USD [11]. ILO started the National Plans of Action for Decent Work and Decent Work Country Programs (NPADW, 2010 - 2015) according to this program the labor law reform is the top priority area in Pakistan. Effective measures can adopt to cut occupational accidents by a collaboration of workers by raising safety awareness among workers and social responsibility among employers. A safety culture shared and 
Various constituted by workers can decrease occupational accidents [8].

\section{Conclusion}

The trend of industrial accidents in factories declined in Pakistan in, but the increased trend of fatal accidents can be a major concern for safety stakeholders. The overall decreasing trend of industrial accidents can associate with improved HDI in Pakistan, but these results are not enough to draw the actual scenario of this public related issues. Future studies can design to investigate the root causes of industrial accidents with more recent data. Due to the deficient literature of occupational health and safety in Pakistan, this study can be useful to understand the occupational health safety performance of factories in Pakistan. Enforcement of safety reporting at government level should make possible so that victims can gain compensation under the regulations and future safety plans can formulate. This study has limitations regarding accidents distribution by industry types, accidents causes, age and sex groups of workers due to lack of epidemiological data on occupational accidents.

\section{References}

1. International Labour Organization (ILO), 2013. Press release at World Day for Safety and Health at Work. ILO calls for urgent global action to fight occupational diseases. [Cited 2015 November 26]. Available from: http://www.ilo.org/ global/about-the-ilo/media-centre/press-releases/ WCMS_211627/lang--en/index.htm.

2. Hämäläinen $P$, Takala J, Saarela KL. Global estimates of occupational accidents. Safety Science. 2006 Feb 28;44 (2):137-56.

3. Hämäläinen P, Saarela KL, Takala J. Global trend according to estimated number of occupational accidents and fatal work-related diseases at region and country level. Journal of safety research. $2009 \mathrm{Dec}$ 31;40(2):125-39.

4. Takala J. Global estimates of fatal occupational accidents. Epidemiology-Baltimore. 1999 Sep 1;10(5):640-6.

5. Pasha TS, Liesivuori J. Country profile on occupational safety and health in Pakistan. Kuopio (Finland): Finnish Institute of Occupational Health; 2003.

6. Abbas M. Trend of Occupational Injuries/Diseases in Pakistan: Index Value Analysis of Injured Employed Persons from 2001-02 to 2012-13. Safety and Health at Work. 2015 Sep 30;6(3):218-26.

7. Rhee KY, Choe SW, Kim YS, Koo KH. The trend of occupational injuries in Korea from 2001 to 2010. Safety and health at work. 2013 Mar 31;4(1):63-70.
8. Unsar S, Sut N. General assessment of the occupational accidents that occurred in Turkey between the years 2000 and 2005. Safety Science. 2009 May 31;47(5):614-9.

9. Macedo AC, Silva IL. Analysis of occupational accidents in Portugal between 1992 and 2001. Safety Science. 2005 Jul 31;43(5):269-86.

10. Pakistan Bureau of Statistics (PBS), 2013. Labour Force Survey 2012-13 (Annual Report), Thirty First issue. [Cited 2015 Novmber]. http://www.pbs.gov.pk/sites/default/files/ Labour\%20Force/publications/Annual\%20Report\%20of\% 20LFS\%202012-13(New).pdf.

11. PLO (Punjab Law online), 2014. THE FACTORIES ACT 1934, Act XXV. [Cited 2015 November 5]. Available from: http://punjablaws.gov.pk/laws/168a.html\#_ftn232.

12. Jorgensen, K. Audits, inspections and investigations: reporting and compiling accident statistics. In: ILO Encyclopedia of Occupational Health and Safety. ILO, Geneva, 1998, pp. 1-31.

13. Rantanen J, Kauppinen T, Toikkanen J, Kurppa K, Lehtinen S, Leino T, Baranski B. Work and health country profiles. Country profiles and national surveillance indicators in occupational health and safety. People and work. Research Reports. 2001; 44:57-66.

14. Shannon HS, Mayr J, Haines T. Overview of the relationship between organizational and workplace factors and injury rates. Safety Science. 1997 Aug 31; 26(3): 201-17.

15. Spangenberg S, Baarts C, Dyreborg J, Jensen L, Kines P, Mikkelsen $\mathrm{KL}$. Factors contributing to the differences in work related injury rates between Danish and Swedish construction workers. Safety Science. 2003 Jul 31; 41(6): 517-30.

16. United Nations Development Programme (UNDP) (2010), Human Development Report (HDR): The Real Wealth of Nations: Pathways to Human Development, New York: UN.

17. Human Development Report 2015, Work for human development, Briefing note for countries on the 2015 Human Development Report, Pakistan. [Cited 2015 November 5]. Available from http://hdr.undp.org/sites/all/themes/ hdr_theme/country-notes/PAK.pdf. 